\title{
DIREITO PENAL DO INIMIGO
}

\author{
Natieli Inês Langner Diel ${ }^{1}$
}

RESUMO: O presente artigo analisará o aumento da violência e da criminalidade a partir da evolução dos ramos da sociedade, sua globalização e da involução de valores que acaba por criar uma ideia geral de insegurança e medo, o que influenciou diretamente as demandas que recaem sobre o direito penal como um todo. O Direito Penal do Inimigo, teoria elaborada por Günther Jakobs, influenciado por Niklas Luhmann, dentro da matéria de criminologia, seria uma resposta trazida por aquele autor à crescente criminalidade. Em sua teoria, Jakobs apresenta a dicotomia cidadão versus inimigo, e a diferença que o Direito Penal deveria dar a ambos diante da prática de um crime, sendo que o primeiro, o cidadão, ao cometer fato delituoso teria do Estado o tratamento baseado na dignidade da pessoa humana, já o inimigo, pessoa que se coloca, por vontade própria, fora da relação cidadão/Estado e atentando contra este e a sociedade, teria tratamento diverso, no qual não teria acesso às garantias processuais e constitucionais, visto que tão grave seriam suas ações que não as mereceria. O Direito Penal do Inimigo, para Günther, seria portanto, uma reação, apesar de radical, à criminalidade cada vez mais violenta e complexa. A metodologia utilizada é bibliográfica e qualitativa.

Palavras-Chave: Direito Penal. Direito Penal do Inimigo. Cidadão. Inimigo. Globalização. Criminalidade.

ABSTRACT: This article will analyze the increase in violence and crime from the evolution of the branches of society, its globalization and the involution of values that ends up creating a general idea of insecurity and fear, which directly influenced the demands that fall on the law criminal law as a whole. The Criminal Law of the Enemy, a theory developed by Günther Jakobs, influenced by Niklas Luhmann, within the field of criminology, would be a response brought by that author to the growing criminality. In his theory, Jakobs presents the citizen versus enemy dichotomy, and the difference that the Criminal Law should give to both in the face of the commission of a crime, with the first, the citizen, when committing a criminal act, the State would be treated based on dignity. of the human person, on the other hand, the enemy, a person who places himself, by his own will, outside the citizen/State relationship and attacking him and society, would have different treatment, in which he would not have access to procedural and constitutional guarantees, since it is so serious it would be your actions that didn't deserve them.

${ }^{\text {I}}$ Pós-Graduação em Gestão em Segurança Pública: Segurança Pública pelo Centro Universitário Leonardo da Vinci - Porto Alegre, RS. Bacharelado em Direito: Ciências sociais e Jurídicas Instituto Cenecista de Ensino Superio Santo ÂNGELO - Santo Ângelo, RS. E-mail: natielidiel@hotmail.com. 
The Criminal Law of the Enemy, for Günther, would therefore be a reaction, albeit radical, to criminality that is increasingly violent and complex.

Keywords: Criminal Law. Criminal Law of the Enemy. Citizen. Enemy. Globalization. Crime.

\title{
INTRODUÇÃO
}

Todo e qualquer grupo social necessita de um ordenamento, de um corpo de regras que o norteie, descrevendo e limitando direitos e deveres daqueles que dão corpo a estes grupos. Eis aí o primordial fato para a existência do Direito e a sua legitimação perante àqueles aos quais abrange.

O Direito Penal, como ramo do Direito, é, mais ainda, imprescindível para o homem enquanto sociedade, pois é nele que se busca a manutenção da ordem e da paz. Sem o Direito Penal e seu sistema, já afirmara Carrara, "seriam as cidades um contínuo teatro de lutas e de guerra sem limite. E aí está porque na tranquilidade reside, segundo meu modo de entender, o verdadeiro fim da pena"(2002. p. 82).

Sendo assim, o Direito Penal se mostra como algo essencial para a vida em sociedade, pois é a ele que se recorre, mesmo como ultima racio, quando há violação dos direitos garantidos pelo ordenamento jurídico.

O Direito Penal, justamente por trazer em si aquilo que é ou não considerado violação de direitos, por tipificar determinados atos, atribuir níveis de sanções, demonstra qual é a ética da sociedade que o criou, é o reflexo da sua moral. Moraes (2011, p.25), neste sentido fala que:

\begin{abstract}
A moral de um povo pode ser facilmente medida pela incidência do Direito. O mínimo ético de uma sociedade é proporcional ao Direito vigente: quanto maior a necessidade do uso do Direito, maior o indício de que o povo está moralmente em crise. É plausível, portanto, a suposição de que quanto menor a necessidade do uso do Direito, mais elevada está a virtude dos homens de determinada sociedade.
\end{abstract}

E qual seria o retrato da sociedade de em que vivemos hoje? Qual é o tamanho do corpo de normas que vemos em nosso sistema jurídico atual?

Segundo Capristano de Abreu o Direito ideal seria composto por uma Constituição Federal que necessitaria apenas de dois dispositivos: “art. Io. Todos 
homem deve ter caráter e art. $2^{2}$. Revogam-se as disposições em contrário".(Apud BONFIM, 1999, p. 71).

Porém essa Constituição jamais daria conta da demanda da atual sociedade, como demonstra Moraes (2011, p.24)

O Direito Penal com mínima intervenção torna-se um sonho cada vez mais distante, sobretudo em ciclos de valores. Contudo, o homem brasileiro também está em crise e imerso em circunstâncias que, de maneira crescente, exigem a intervenção do Direito para a efetiva tutela de bens garantidos pela Constituição Federal.

Torna-se mais clara esse entendimento de que a moral de um povo está diretamente ligada à intervenção do Direito de que ela necessita, quando, por exemplo, vê-se a criação do um Estatuto da Criança e do Adolescente, para dizer que uma criança não pode passar fome, um Estatuto do Idoso, para dizer que uma pessoa idosa necessita de amparo, uma Lei Maria da Penha, para dizer que não se pode agredir a uma mulher. Sendo assim criadas inúmeras novas legislações, fenômeno ao qual chamamos de hipertrofia legislativa, que sedimenta a sociedade em subgrupos (as crianças, os idosos, as mulheres, os homossexuais) e cria novos sujeitos passivos. Não bastaria dizer que todo ser humano, independente de idade, cor, sexo, etnia, deve ser respeitado e atendida duas necessidades, pelo simples fato de ser alguém. Pelo que a legislação demonstra não, pois hipertrofiada acaba criando novos bens jurídicos e na força desses novos movimentos sociais de emancipação surge um grande desejo punitivo em diversos setores da opinião pública, o que vai exigindo cada vez mais uma intervenção máxima do Estado, indo contra o princípio da intervenção mínima, fazendo que com que o Direito Penal não seja mais a ultima racio que deveria ser.

Essa inegável crescente demanda da sociedade para com o Direito nos demonstra claramente que estamos vivendo uma grande crise de valores humanos. Pois tantas e tão profundas foram as mudanças que a sociedade passou e vem passando que o certo e o errado são variáveis constantes. Pais e professores já não possuem mais a mesma autoridade que outrora. Os ladrões hoje ventem-se bem. A competitividade tão estimulada faz de um colega nosso maior inimigo. $O$ consumismo nos ensina que, venha de onde vier, o mais importante é possuir. E 
diante de tal situação é de suma importância que o Direito cada vez mais regulamente o comportamento humano. Hungria, citando Aloísio de Carvalho, faz o seguinte comentário sobre o homem em crise:

\begin{abstract}
o mundo contemporâneo passa por uma grave crise social e moral, que remota a primeira Grande Guerra. Fendeu-se a camada de verniz que recobria os instintos egoísticos e violentos e estes predominaram na orientação da conduta humana. As normas de cultura que os séculos haviam sedimentado vêm sendo extirpadas pelas raízes ou abolidas com a mesma facilidade com que se repudiam hábitos recentes. Desintegra-se, cada vez mais o espírito de cooperação, de ordem e de paz. A fé religiosa foi banida dos corações. Os escrúpulos e reservas ditados pelo velho Código moral saíram de voga, como o fraque e a barba ando, e um exacerbado egoísmo desembestou na steeple chase do "cada um para si, custe o que custar". (1955, p.53).
\end{abstract}

Além do mais a sociedade atual, rotulada de pós-moderna, pós-industrial e globalizada vive novos paradigmas como a comunicação instantânea, o avanço tecnológico, a maximização da riqueza e eficiência econômica primados pelo modelo de Estado, que também se apresenta como situação de crise, uma vez que junto com esses novos modelos de vida, surgem novos modelos de crimes e violações.

A globalização, que teve na expansão econômica, sua maior razão, que resultou na redução dos espaços geográficos e crescimento do comércio exterior, fortalecendo o poder econômico de empresas multinacionais, a revolução da tecnologia e dos meios de comunicação, o grave ataque ao meio ambiente e seus efeitos devastadores, tudo isso acompanhada da falta de um ordenamento político mundial, resulta num enfraquecimento do Estado, pois nem ele nem o Direito conseguem dar conta de toda essa demanda, que ultrapassou as fronteiras e tomou proporções mundiais. Neste sentido Batista Jr (1996, p.2), já asseverava que a globalização é "um processo em curso que domina de maneira inexorável a economia mundial e tende a destruir fronteiras nacionais" e assim “os Estados nacionais estariam em crise ou declínio irreversíveis”.

A metodologia utilizada neste artigo é bibliográfica e qualitativa. Para Gil (2008), o uso da abordagem qualitativa propicia o aprofundamento da investigação das questões relacionadas ao fenômeno em estudo e das suas relações, mediante a máxima valorização do contato direto com a situação estudada. Para Fonseca (2007) 
,a pesquisa bibliográfica é feita a partir do levantamento de referências teóricas já analisadas, e publicadas por meios escritos e eletrônicos, como livros, artigos científicos, páginas de web sites.

\section{DESENVOLVIMENTO DE UMA CONSCIÊNCIA DO MEDO E O SURGIMENTO DO DIREITO PENAL DO RISCO}

Todas essas mudanças e novos paradigmas sociais, de alcances mundiais, interferiram diretamente no bem-estar social de cada pessoa. A sociedade atual de consumo, superdesenvolvida tecnologicamente e extremamente competitiva marginalizou um grande número de indivíduos os quais passaram imediatamente a representar uma grande ameaça tanto para si próprio como para sua família e também em relação aos seus bens materiais. Sendo considerados como ameaça, essas pessoas passaram a serem vistas como um possíveis causadoras de riscos dentro dessa sociedade tão complexa, consequentemente gerando medo e sentimento de insegurança. Como assim explica Moraes (2011, p.50):

os riscos modernos, acentuados pelas inovações trazidas à humanidade (globalização da economia e da cultura, meio ambiente, drogas, o sistema monetário, movimentos migratórios, aceleração do processamento de dados ect), invariavelmente geram uma reação irracional e irrefletida por parte dos atingidos. Disso decorre a insegurança e o medo que têm impulsionados frequentes discursos postulantes de uma tutela da segurança pública, em detrimento de interesses puramente individuais.

Essa nova sociedade que, para o indivíduo representa uma grande difusora de graves ameaças, refletiu diretamente no Direito Penal. Essa temática e suas consequências, como recorda Silva (2004, p.93-94).

\footnotetext{
Foram amplamente analisados e criticadas pela Escola de Frankfurt, originalmente por Prittwitz, o qual já observava o surgimento de um 'Direito Penal do risco' (Riskostrafrecht) que, longe de aspirar conservar seu caráter fragmentário, como ultima racio, tem se convertido em sola racio, mais precisamente um Direito Penal expansivo...”.
}

A sociedade, amedrontada por ameaças vindas de todos os lados, passou a considerar o Direito como seu refúgio, exigindo-se assim que seu caráter de ultima racio fosse superado e se expandisse, dando origem ao Direito Penal do risco, que seria em síntese uma tutela preventiva. Essa mesma sociedade passou a clamar uma ação anterior a qualquer ato considerado ameaçador, onde a tutela é acionada 
anteprevendo os atos considerados de risco. E isso tem suas consequências como bem demonstra Moraes (20II, p. 49) ao falar que:

\begin{abstract}
o caráter 'expansivo' do chamado 'Direito Penal de risco' vem acolhendo novas demandas e interesses pessoais e antecipando a tutela penal (com tipificações abertas e amplas, mediante o uso de tipos de perigo abstrato, mera conduta, omissivos impróprios etc). Tanto na legislação pátria quanto na estrangeira, o 'Direito Penal do risco' vem permitindo a adoção de uma política criminal pautada pela preocupação incessante de criminalizar e prevenir a criminalidade organizada, a corrupção, o tráfico ilícito de entorpecentes, a criminalidade econômica, o terrorismo e os crimes contra a humanidade, primeiros sinais da tendência de perenizar um Direito Penal de 'terceira velocidade' - o 'Direito Penal do Inimigo'.
\end{abstract}

Neste mesmo sentido Silva (2004, p. 95) relata que esses fatos têm provocado uma mudança de perspectiva da própria dogmática penal e do direito de punir:

\footnotetext{
...se se analisar os fins aos quais o Direito Penal do risco pretende servir sociologicamente segundo a ideia de risco, a saber, por um lado, a minimização do risco e, por outro, a produção de segurança, circunscrevendo-os na linguagem jurídico-penal, trata-se da ideia de prevenção, de proteção dos bens jurídicos através de uma orientação pelo risco e de estabilização da norma.
}

Ou seja, essa ideia de medo e sensação de insegurança, muitas vezes difundida e ampliada pelos meios de comunicação, enraizou-se na consciência de cada cidadão, os quais passaram a clamar ao Estado uma resposta, a qual recaiu sobre o Direito Penal como um Direito Penal de prevenção. Clamar por segurança, por motivos óbvios, é legítimo, visto que tal aspiração inclusive encontra-se compilada em nossa Carta Magna, tanto quanto em tratados internacionais aos quais nosso país firmou participação. Mas não é aí que se encontra o problema e sim em tornar isso a matriz do Direito Penal, uma vez que a sua essência não é prevencionista. Lyra (1977, p.97) já advertira que:

\footnotetext{
a repressão da criminalidade político-social desmascara-se à plena luz, ou pior, à plena treva, os interesses que o Estado representa. Ao menor sinal de perigo, a ordem torna-se a desordem absoluta. Dissolve tudo, corrompe todos. Sacrifica-se, de repente das formalidades legais aos princípios morais, por medo, ódio ou vingança.
}

Nessa mesma linha de reflexão, que fala sobre o homem de hoje, que se acostumou a viver com as facilidades e os confortos que a modernidade e a tecnologia trouxeram, ao menor sinal de dor reage negativamente a isso, pois desaprendeu a enfrentá-la estimulado por uma sociedade de mercado que oferece e vende as mais 
variadas opções de "não sentir dor" como ainda Lyra (1977, p.97) "homem de hoje está pouco preparado para sofre; qualquer dor é interpretada como um estímulo para tomar remédios adequados com a finalidade de evita-la ou suprimi-la”.

Diante disso pode-se perceber que o medo realmente institucionalizou-se em nossa sociedade a ponto de perpetrar a íntima consciência de cada indivíduo que a compõe, que se vê uma possível vítima de riscos vindos de todos os lados e de qualquer um. Vive-se hoje em uma sociedade que vislumbra diariamente a sensação de insegurança, fomentada pelo grande crescimento da criminalidade de massa, pelo surgimento da criminalidade organizada, pelo surgimento de novas modalidades de lesões aos bens jurídicos, tudo isso incrementado pela forte atuação sensacionalista da mídia e pelo declínio dos valore sociais, éticos e morais. Porém, esse medo institucionalizado não ficou reprimido, insurgiu-se como nova demanda para o Direito Penal, pois é nele que esse homem amedrontado busca alento para sua insegurança.

\section{SURGIMENTO DO DIREITO DE 'TERCEIRA VELOCIDADE'}

Visto que a função de punir alguém por ato considerado um malefício é exclusiva do Estado, e a qual através de nosso sistema democrático de direito também se revela como um poder-dever estatal, não seria nada mais natural esperar do Estado a atitude necessária que vise um controle eficaz das ações humanas para a busca e manutenção da paz social. Porém a expansão e o desenvolvimento da sociedade se deu de uma maneira tão brutalmente veloz, consequentemente gerando tantas novas situações de conflito, de lesões, de violações, muitas vezes se quer ainda tipificadas. Eis aí o grande desafio que o Direito Penal passou a enfrentar: qual seria a melhor resposta a dar frente a essas novas demandas? Como combater esses novos problemas? De que madeira agir e reagir para novamente ter-se o equilíbrio e a manutenção social?

Como resposta a essas indagações, podemos apontas alguns movimentos modernos de políticas públicas, como Lei e Ordem, Tolerância Zero ou Broken Windows, movimentos da escola clássica, adotados em países como os EUA, que 
representaram um severo trato quanto às questões penais atuais, indo ao endurecimento da penalização, agravamento das reprimendas, maior liberdade de atuação policial. Apesar de no Brasil ter-se constatado movimentos pautados na escola penal positiva ou iluminista, quais sejam a adoção de critérios alternativos à pena privativa de liberdade, percebe-se claramente uma inclinação da dogmática penal à adoção de correntes mais rigorosas.

Alexandre de Moraes (2011, p.7I) nos explica que

\begin{abstract}
inicia-se, dentro de todo o contexto já traçado, a institucionalização de políticas públicas que divergem completamente do modelo clássico (pena de prisão com amplas garantias penais e processuais) e do modelo de Direito Penal de 'segunda velocidade' (mitigação de garantias penais e processuais, consensos, barganhas e penas alternativas à prisão). Começa, pois, a aparecer, silenciosamente, nas legislações e modernas políticas de combate a estas formas de criminalidade, o que Günther Jakobs denomina de 'Direito Penal do Inimigo'. Trata-se do advento de um Direto de 'terceira velocidade' pautado por flexibilização de direitos e garantias penais e processuais, antecipação da tutela penal, adoção de tipos de perigo abstratos e normas penais em branco, concomitantemente com a adoção de regimes rigorosos de cumprimento de penas privativas de liberdade. Estamos assistindo ao despertar das primeiras acepções das políticas criminais voltadas ao combate dos 'inimigos'.
\end{abstract}

Nesse mesmo diapasão Sanchez(2002, p.75) dá seu prognóstico:

O Direito Penal da globalização econômica e da integração supranacional será um Direito já crescentemente unificado, mas também menos garantista, no qual se flexibilizarão as regras de imputação e se relativizarão as garantias político-criminais, substantivas e processuais.

Vê-se, nítido, que a complexidade dos crimes atuais (tráfico internacional, terrorismo, lavagem de dinheiro etc), que não são mais apenas os crimes cujo os quais o Direito Penal enfrentava, sejam eles, crimes cometidos de formas isolada e por apenas um agente, como por exemplo, um roubo, um homicídio, visto que aqueles crimes são complexos por sua natureza de organização criminosa e por afetarem diretamente em outros sistemas da sociedade, como o sistema econômico, têm trazido reflexos na atuação do Direito no sentido de não mais identificar o crime e seu autor, aplicando a sanção previamente estabelecida em lei, mas analisar e valorar o potencial perigo que tais crimes complexos e seus autores detém, identificando-os como verdadeiros inimigos da sociedade, concluindo-se disso que tais crimes e delinquentes (inimigos) merecem um tratamento diferenciado, o qual 
significaria uma flexibilização das normas penais, um menor atendimento às garantias processuais e uma intervenção estatal mais rigorosa e inclusive antecipada. Gomes e Bianchini ( 2004, p. I08-109). falando sobre essa transição do modelo clássico penal de ultima racio para as modernas tendências, destacam que:

na base atual do Direito penal, consequentemente, além de uma crise evidente, parece residir um irrefutável contradição: por um lado, justamente porque se pretende que ele cumpra um papel (missão) de tutela de bens jurídicos para a manutenção da paz social, foi gradualmente transformandose em um instrumento de prevenção política-social; por outro, quanto mais se incrementa essa função, mais a sociedade se dá conta da falta de operatividade do sistema e da ausência de uma verdadeira tutela dos bens jurídicos. Com isso o que resulta de concreto é uma função puramente simbólica de proteção, que se caracteriza então não só pela flexibilização dos princípios jurídicos e das garantias, senão especialmente pela antecipação da intervenção estatal.

Ainda dentro desse sentindo pode-se citar Hassemer, que observando o panorama mundial, afirma que a ideia de prevenção que vem se exigindo do Direito Penal, surge como uma forma terapêutica para o sentimento de insegurança que se difundiu entre as pessoas e a sociedade como um todo. Segundo ele "há uma tendência do delinquente a converter-se em inimigo, e o direito penal, em um direito penal para o inimigo". E acrescenta:

acontecendo isso, tem-se um retorno à velha visão da criminologia clássica, que concebia o delito como um enfrentamento formal, simbólico e direto entre dois rivais - o Estado e o infrator -, os quais travam um maniqueísta conflito entre o bem e o mal. Um personificava o lado bom da sociedade, sem máculas, perfeito, congregando os justos e pacíficos; o outro, o perigoso delinquente, tumor a ser extirpado o mais rápido possível, com o fito de sanear novamente o corpo social. (apud BONFIM, 1997. p. I13).

Como se vê, é sem dúvida, todas essas mudanças sociais que deram origem à institucionalização do medo e da sensação de insegurança e dessas descendem as novas demandas em relação a ação Estatal frente a criminalidade expandida e globalizada. E como agir, de maneira racional, sem gerar mais instabilidade e um possível descrédito por parte do Poder Estatal? Pois toda essa gama de novas e complexas situações faz com que toda tomada de decisão seja de igual complexidade e dificuldade, pois a criminalidade hoje engloba muitos mais setores da sociedade que apenas o sistema penal e até onde o Direito Penal pode ir? Até onde ele dispõe de condições para lançar sua tutela? Seria mesmo dever do Direito Penal a panaceia para 
a atual situação? E esses novos paradigmas trazidos pelas mudanças sociais seriam um bom motivo para a dogmática jurídica adotar teorias como o Direito Penal de terceira velocidade? Nesse sentido advertem Gomes e Bianchini (2004, p. 34):

Impõem-se definir com toda clareza para que serve o Direito Penal. Esse sempre foi o grande desafio da ciência penal. Não se pode atribuir a ele papel que nunca conseguirá desempenhar. Valendo-se da imagem do elefante e dos ratos, dá para dar uma ideia (bastante aproximada) do que vem acorrendo com o tradicional Direito Penal, que é, em termos de velocidade, um verdadeiro elefante (tendo em conta que se funda na pena de prisão e exige, consequentemente, o devido processo legal clássico: investigação burocratizada, denúncia, provas, instrução demorada, contraditório, ampla defesa, sentença, recursos, tribunais lentos e abarrotados etc.). A criminalidade da era pós-industrial e, agora, da globalização, por seu turno, é velocíssima (tanto quanto os ratos). Ao longo do século $\mathrm{XX}$, mas particularmente depois da Segunda Guerra Mundial, acreditou-se que seria possível conter ou controlar ("combater") os ratos com o elefante (com o Direito penal tradicional), desde que alguma mobilidade extra lhe fosse dada. O legislador, assim, começou a sua deformação, colocando algumas rodas mecânicas nas suas patas (leia-se: para fazer frente à criminalidade moderna, começou a transformar o Direito penal tradicional flexibilizando garantias, espiritualizando o conceito de bem jurídico, esvaziando o princípio da ofensividade - mediante a construção de tipos de perigo abstrato -, eliminando grande parcela da garantia da legalidade etc).

Alexandre de Moraes (20II, p.8I) encerra com grande pontualidade esse

questionamento em torno da legitimidade de novas teorias penais frente à atual realidade ao acentuar que:

Entender e questionar a legitimidade de um Direito Penal para o 'inimigo da sociedade' pressupõe, pois, entender o contexto da realidade do Direito Penal; pressupõe entender como o Direito bem sendo contaminado por ideia estranhas ao seu código operativo e como novas demandas decorrentes dos avanços tecnológicos, da globalização e da aceleração da comunicação vêm modificando o Direito Penal clássico.

\section{DIREITO PENAL DO INIMIGO: CONCEITO E SIGNIFICADO}

Para entender o Direito Penal do Inimigo, faz-se necessário entender a distinção que Günther Jakobs faz entre quem seria cidadão e quem seria o inimigo. Para ele o cidadão é aquela pessoa que aceita o contrato social entre si e o Estado, abrindo mão de uma parcela de sua liberdade em prol do benefício de todos. $\mathrm{O}$ cidadão portanto se torna parte desse contrato, submetendo-se às leis e assumindo seus deveres perante a sociedade e o Estado, como a outra parte do contrato, também cumprindo seu papel, garante a este cidadão seus direitos, respeitando sua dignidade 
enquanto ser humano. $O$ inimigo seria alguém que, por sua própria consciência, não aceitaria se submeter ao contrato social e às regras contidas nele. Não fazendo parte desse contrato, por sua própria vontade, não teria direito às garantias asseguradas pelo Estado. Como bem explica Moraes (2011, p.30):

O inimigo é o indivíduo que cognitivamente não aceita submeter-se às regras básicas do convívio social. Para ele, dirá Jakobs, deve-se pensar em um Direito Penal excepcional, de oposição, um Direito Penal consubstanciado na flexibilização de direitos e garantias penais e processuais. Há que se pensar em um novo tratamento que a sociedade imporá àquele que se comporta, cognitivamente, como seu inimigo. Um tratamento que não se amolda às diretrizes do Direito Penal clássico, mas que poderia ser, em tese, legitimado constitucionalmente.

:Na própria concepção de Jakobs (2003, p. 57),

O não-alinhado é um indivíduo que, não apenas de maneira incidental, em seu comportamento (criminoso grave) ou em sua ocupação profissional (criminosa grave) ou, principalmente, por meio de vinculação a uma organização (criminosa), vale dizer, em qualquer caso de forma presumivelmente permanente, abandonou o direito e, por conseguinte, não garante o mínimo de segurança cognitiva do comportamento pessoal e o manifesta por meio de sua conduta.

Ainda sobre a distinção entre cidadão e inimigo para Jakobs (2003, p.III)

A definição do autor como inimigo do bem jurídico, segundo o qual poderiam ser combatidos já os mais prematuros sinais de perigo, embora isso possa não ser oportuno no caso concreto, deve-se contrapor aqui uma definição do autor como cidadão. $O$ autor não somente deve ser considerado como potencialmente perigoso para os bens da vítima, como deve ser definido também, de antemão, por seu direito a uma esfera isenta de controle; e será mostrado que o status de cidadão podem se derivar limites, até certos pontos firmes, para as antecipações de punibilidade.

Contribuindo para um melhor entendimento sobre a da teoria de Sanchez (2002,p.140) realça que:

O inimigo é um indivíduo que, mediante seu comportamento, sua ocupação profissional ou, principalmente, sua vinculação a uma organização, abandona o Direito de modo supostamente duradouro e não somente de maneira incidental. Em todo caso, é alguém que não garante mínima segurança cognitiva de seu comportamento pessoal e manifesta esse déficit por meio de sua conduta.

(...) Se a característica do inimigo é o abandono duradouro do Direito e ausência da mínima segurança cognitiva em sua conduta, então seria plausível que o modo de afrontá-lo fosse com o emprego de meios de asseguramento cognitivo desprovido da natureza de penas. 
Para Jakobs, quem por escolha própria e de modo permanente prática atos delituosos, se negando a agir conforme as regras e leis da sociedade a qual se encontra, deverá ser visto e tratado como um inimigo desta, pois considera que um indivíduo ao infringir o contrato social se coloca fora dele e deixa de ser membro do Estado e por isso deverá ser tratado não como pessoa, mas sim como coisa. Perdendo esse status de pessoa, consequentemente perderá os direitos inerentes ao cidadão e terá que ser castigado como inimigo, visto que quem por princípio escolhe a vida do crime, não oferece garantia de um comportamento adequado e por isso não pode ser tratado como cidadão e sim como inimigo, que deve ser combatido e eliminado. Jakobs (2003,p.55) exemplifica tais premissas dizendo que

\begin{abstract}
Além da certeza de que ninguém tem o direito de matar, deve existir também a de que com um alto grau de probabilidade ninguém vá matar. Agora, não somente a norma precisa de um fundamento cognitivo, mas também a pessoa. Aquele que pretende ser tratado como pessoa deve oferecer em troca uma certa garantia cognitiva de que vai se comportar como pessoa. Sem essa garantia, ou quando ela for negada expressamente, o Direito Penal deixa de ser uma reação da sociedade diante da conduta de um de seus membros e passa a ser uma reação contra um adversário.
\end{abstract}

Diante da conceituação do Direito Penal do Inimigo, nota-se que ele traz consigo um conceito que versa sobre uma flexibilização de garantias penais e processuais fundamentais também refletindo diretamente na teoria da pena, seus fundamentos e finalidades. Mas no que isso realmente implicaria? Gomes (out./2004) de uma maneira clara e objetiva, elucida seu entendimento sobre a teoria de Jakobs, sintetizando, na prática o que ela representaria, como por exemplo, o inimigo, não poderia ser punido com pena, mas sim, com medida de segurança, visto sua periculosidade; determinadas garantias processuais seriam suprimidas ou ao menos relativizadas; o inimigo não poderia ser punido conforme sua culpabilidade e sim conforme sua periculosidade; as medidas contra o inimigo não levariam tanto em conta o que ele fez, mas o que ele poderia fazer no futuro, se representasse um perigo ou não, sendo assim um direito penal prospectivo, que se projeta do momento do crime em diante; o inimigo não seria visto como sujeito de direito, mas como um objeto de coação; o cidadão ao delinquir continuaria com seu status de pessoa, já o inimigo perderia tal status; o Direito Penal do cidadão manteria vigência de norma, o 
Direito Penal do Inimigo seria instrumento de combate contra perigos; o Direito Penal do inimigo adiantaria o âmbito da norma, o que significaria uma antecipação da tutela; em relação a pena, mesmo que fosse desproporcional, ainda assim se justificaria sua antecipação e aplicação, visto que a pena passaria a ter uma função não de punição, mas de reafirmação da norma e intimidação dos demais. E continua Gomes (2004), dizendo que:

Direito penal do cidadão é um Direito penal de todos; o Direito penal do inimigo é contra aqueles que atentam permanentemente contra o Estado: é coação física, até chegar à guerra. Cidadão é quem, mesmo depois do crime, oferece garantias de que se conduzirá como pessoa que atua com fidelidade ao Direito. Inimigo é quem não oferece essa garantia.

Inimigo, portanto, seria aquela pessoa que, por opção e desafiando as leis, teria no crime um modo de vida, caracterizando-se em uma ameaça constante à manutenção da paz social. $O$ direito como resposta e para não cair em descrédito diante daqueles que, submetendo-se ao ordenamento jurídico, teriam status cidadão, reagiria de forma radical para extirpar tais inimigos, através de um ordenamento, $\mathrm{O}$ Direito Penal do Inimigo, que lhe permitisse agir além dos limites consolidados pelo estado democrático de direito. Tal reação teria por escopo a reafirmação da vigência de suas normas, o que seria a própria finalidade da pena de tal ordenamento, através, não da punição de um crime, mas de um verdadeiro combate a um inimigo.

\section{CONCLUSÃO}

Como foi visto no início, o corpo de leis de uma sociedade reflete sua moral e ética, consequentemente o Direito Penal também é o reflexo do povo que o criou. Se o Direito Penal hoje está em discussão, isso quer dizer que está se vivendo um momento de crise. Se há crise é porque o atual ordenamento não está mais dando conta da demanda que surge. E se os meios aos quais a sociedade dispõe para a manutenção da paz e ordem social não estão mais sendo eficazes, não há nada mais certo que a sociedade repensar seus modelos e sistemas jurídicos. Não se trata aqui, de dizer que o Direito Penal do Inimigo, formatado por Günther Jakobs, é ou não um modelo a ser seguido, mas de dizer o quanto se faz importante repensar o Direito Penal e as políticas criminais diante da nova criminalidade de massa, transnacional, 
cujos autores cada vez mais audaciosos, desafiam constantemente a ordem social e jurídica. Qual caminho adotar? Há possibilidades de reverter essa nova criminalidade de massa e transnacional? Trazer flexibilidade à norma penal e processual penal seria uma maneira de oportunizar o Direito a se expandir para alcançar essa nova demanda ou representaria uma ameaça à segurança jurídica e ao estado democrático de direito? Apenas com uma análise racional e sóbria, sobre a realidade que se enfrenta e sobre onde se pretende chegar, sem julgamentos e atitudes precipitadas, é que se obterá a eficaz resposta que a sociedade vem clamando e que ainda não foi encontrada.

\section{BIBLIOGRAFIA}

Alflen DA SILVA, Pablo Rodrigo. Leis Penais em Branco e o Direito Penal do Risco: aspectos críticos e fundamentais. Rio de Janeiro: Lumen Juris, 2004. p. 93-94).

BATISTA JR, Paulo Nogueira. O Mito da Globalização. Disponível no periódico Folha de S. Paulo, edição de 30 de maio de 1996, 2º Caderno, p.2.

BONFIM, Edilson Mougenot. Direito Penal da Sociedade. São Paulo: Oliveira Mendes. Del Rey: 1997.

BONFIM, Edilson Mougenot. Os Reflexos da Constituição Cidadã no Processo Penal. 'Os Dez Anos da Constituição Cidadã e os seus reflexos nos demais ramos do Direito'. Revista OAB Mato Grosso do Sul. Campo Grande, a. I, n. I, 1999)

CARRARA, Franscesco. Programa do Curso de Direito Criminal: Parte Geral. Campinas: LZN, 2002.

FONSECA, R. C. V. da. Como elaborar projetos de pesquisa e monografias: guia prático. Curitiba: Imprensa Oficial, 2007

GIL, A. C. Como elaborar projetos de pesquisa. 4. ed. São Paulo: Atlas, 2008. HASSEMER, El Destino de los derechos del cidadano em un derecho penal eficaz. Estudios Penales y Criminológicos, n. XV/183 e II (apud BONFIM, Edimilson Mougenot. Direito Penal..., p. I13) 
HUNGRIA, Nelson Hoffbauer. Comentários ao Código Penal. $3^{\text {o }}$ Edição. Rio de Janeiro: Forense, 1955.

JAKOBS, Günther. Ciência do Direito e Ciência do Direito Penal. Tradução de Maurício Antonio Ribeiro Lopes. São Paulo: Manole, 2003. v. I. Coleção Estudos de Direito Penal.

LYRA, Roberto. Direito Penal Normativo. 2. ed. Rio de Janeiro: José Konfino, 1977.

MORAES, Alexandre Rocha Almeida de. Direito Penal do Inimigo: a terceira velocidade do direito penal. Curitiba: Juruá, 2011.

SANCHEZ, Jesús-Maria Silva. A Expansão do Direito Penal: Aspectos da política criminal das sociedades pós-industriais. Tradução de Luiz Otávio de Oliveira Rocha. São Paulo: Revista dos Tribunais, Série: As Ciências Criminais do Século XXI, 2002. V. II.

GOMES, Luiz Flávio. Direito Penal. Parte Geral: Teoria constitucionalista do delito. São Paulo: Revista dos Tribunais, 2004. v. 3.

.Direito Penal do Inimigo (ou inimigos do Direito Penal). São Paulo: Notícias Forenses, out/2004)

BIANCHINI, Alice. Delitos Sócios-Econômicos: "Eficientismo" a todo Custo. Disponível em: 〈http://www.tribunapr.com.br/noticias/delitossocioeconomicos-eficientismo-a-todo-custo. Acesso em o7 de julho de 2017. 